\title{
Selenium supplementation to chronic kidney disease patients on hemodialysis does not induce the synthesis of plasma glutathione peroxidase
}

\author{
Bronislaw A. Zachara ${ }^{1,3 凶}$, Jolanta Gromadzinska1, Zbigniew Zbrog ${ }^{2}$, Rafal Swiech², \\ Wojciech Wasowicz ${ }^{1}$, Ewa Twardowska ${ }^{1}$, Ewa Jablonska ${ }^{1}$ and Wojciech Sobala ${ }^{1}$ \\ ${ }^{1}$ Department of Toxicology and Carcinogenesis, Nofer Institute of Occupational Medicine, Eódź, Poland; \\ ${ }^{2}$ B. Braun Avitum Dialysis Center, Łódź, Poland; ${ }^{3}$ Higher School of Health Sciences, Bydgoszcz, Poland
}

Received: 24 November, 2008; revised: 22 January, 2009; accepted: 14 February, 2009 available on-line: 24 February, 2009

\begin{abstract}
Background: Numerous authors have shown that selenium (Se) concentration and glutathione peroxidase (GSH-Px) activity in plasma of chronic kidney disease (CKD) patients are lower than in healthy subjects, but there are only few publications on the level of GSH-Px protein in those patients and no reports on the effect of Se supplementation to HD patients on the level of this enzyme. Subjects and Methods: Se concentration and GSH-Px protein level in plasma were measured in a group of 30 CKD patients on hemodialysis (HD) supplemented with $200 \mu \mathrm{g}$ Se/day for 3 months, and 28 patients on HD administered with placebo. Se concentration was measured by graphite furnace atomic absorption spectrometry and plasma GSH-Px protein level by the sandwich ELISA method using polyclonal antibody specific for human plasma GSH-Px. Results: Se concentration in patients on placebo did not change throughout the 3-month study period, but increased significantly in Se supplemented group. Se supplementation to CKD patients on HD had no effect on the level of GSH-Px protein. Conclusions: The lack of GSH-Px protein in CKD patients on HD is not linked to Se deficiency since the level of this element increased after Se supplementation while enzyme protein level did not change. The damaged kidney of HD patients is unable to synthesize GSH-Px, even after induction with selenium.
\end{abstract}

Keywords: chronic kidney disease, glutathione peroxidase, hemodialysis, plasma, selenium supplementation

\section{INTRODUCTION}

There is increasing evidence of oxidative stress in chronic kidney disease (CKD) patients, particularly those on hemodialysis (HD) (Rico et al., 2006). Selenium (Se) and some other trace elements play an important role in biological systems, being components of enzymes which participate in eliminating reactive oxygen species (ROS) (Zima et al., 1998). Glutathione peroxidases (GSH-Pxs) are involved in ROS detoxification. They catalyze the reduction of hydrogen peroxide and a variety of organic hydroperoxides, using glutathione as the reducing agent. GSH-Pxs are implicated in protect- ing cell membrane lipids, proteins and DNA against oxidative stress and are widely believed to be major components of the human antioxidant defense (Papp et al., 2007).

To date, five structurally and functionally distinct forms of GSH-Pxs have been identified in mammalian tissues and all are selenium-dependent (Kyriakopoulos \& Behne, 2002; Brigelius-Flohe, 2006; Papp et al., 2007). Two forms of GSH-Px have been identified in the blood (Yoshimura et al., 1996): 1) cellular GSH-Px (GSH-Px 1) found in red blood cells, and 2) extracellular GSH-Px (GSH-Px 3) found in plasma. In healthy individuals, kidneys have the highest concentration of plasma GSH-Px mRNA, be-

${ }^{\square}$ Corresponding author: Bronislaw A. Zachara, Nowodworska 33/67, 85-120 Bydgoszcz, Poland; tel.: (48) 52 582 04 06; or (48) 601276 074; e-mail: bronzach@yahoo.com

Abbreviations: CKD, chronic kidney disease; GSH-Px, glutathione peroxidase; HD, hemodialysis; ROS, reactive oxygen substances. 
ing the main source of this enzyme (Chu et al., 1992; Avissar et al., 1994). Some authors (Zachara et al., 2000) have shown that in patients on HD Se supplementation has no effect on plasma GSH-Px activity, while others (Saint-Georges et al., 1989; Richard et al., 1993) found that after Se administration the activity of this enzyme increases.

Analysing the GSH-Px protein concentration in plasma of CKD patients, Yoshimura et al. (1996) found only a trace amount of the enzyme, in some cases even below the level of determination. On the other hand, Yamamoto and coworkers (1995) have shown one third of the level found in healthy volunteers, while Roxborough and coworkers (1999) and Donica (2001) observed no differences between patients on HD and healthy controls. So far nobody has studied the effect of Se supplementation on GSH-Px protein level in CKD patients. Therefore, the aim of our study was to measure Se concentration and GSH-Px protein level in plasma of CKD patients on HD, supplemented with Se.

\section{MATERIAL AND METHODS}

Patients and controls. A 3-month, randomized double-blind, placebo-controlled trial was carried out. The study groups consisted of: 1) 30 patients (mean age, $61.0 \pm 11.6$ years) in the end-stage of CKD, treated with regular HD for $24.7 \pm 20.1$ months and supplemented with $200 \mu \mathrm{g}$ Se/day (as Se-rich yeast, Pharma Nord, Bioselenium, Denmark) and 2) 28 patients (mean age, $56.0 \pm 12.0$ years), administered with placebo (bakers yeast, Pharma Nord). The patients were dialyzed 3 times a week for $4 \mathrm{~h}$. 3) The results were compared with 52 healthy volunteers (mean age $51.0 \pm 8.7$ years).

Methods. Blood samples were drawn from all patients before HD session into vacutainer tubes containing lithium heparin as anticoagulant. After centrifugation $\left(+4^{\circ} \mathrm{C}, 5000\right.$ r.p.m., $\left.10 \mathrm{~min}\right)$, the plasma was harvested and stored at $-20^{\circ} \mathrm{C}$ until analysis. Creatinine concentration was determined by routine laboratory method using Jaffy reaction (a kit produced by Cormay, Lublin, Poland). Plasma Se concentration was determined by graphite furnace atomic absorption spectrometry according to the method of Neve and coworkers (1987) using a Unicam 989 QZ Solaar apparatus and the values were expressed as nanogram per millilitre. The accuracy of the method was checked with serum reference material (Nycomed, Oslo, Norway, batch No. 605113). The mean Se level of reference plasma was $78.0 \mathrm{ng} / \mathrm{ml}$, while that obtained in our laboratory was $77.4 \pm 5.0 \mathrm{ng} / \mathrm{ml}$. Plasma GSH-Px protein level was measured by the sandwich ELISA method (Calbiochem, Glutathione Peroxidase Elisa Kit, No.
353918; www.emdbiosciences.com/pathways) using polyclonal antibody specific for human plasma GSHPx. For color reaction, covalently linked streptavidin, alkaline phosphatase (AP) and AP substrate, $p$-nitrophenylphosphate, were used. Plasma samples were diluted 200-fold in sample diluting buffer immediately before analysis. Purified human plasma GSH-Px was used as a standard. Samples with low or high protein values were analyzed 2 or 3 times. The study protocol was approved by the Institute of Occupational Medicine Ethics Commission for Medical Research No. 18/2003. The nature and purpose of the study was explained to the participants and their written consent was obtained.

Statistical analysis. Comparisons of the levels under study at three time points (before the study, one month and three months after study) were made by multivariate analysis of variance (Morrison, 1990). When significant differences were obtained between the groups, the differences were tested at all time points. The tests were based on Shapiro-Wilks' statistics, significance being set at 0.05. All statistics were conducted using the STATA 9 package.

\section{RESULTS AND DISCUSSION}

Mean plasma Se concentration in both groups of HD patients (+ Se and placebo taken together) before the study was $41.9 \pm 10.6 \mathrm{ng} / \mathrm{ml}$ and this value was significantly lower $(P<0.0001)$ than in the control group $(52.2 \pm 11.0 \mathrm{ng} / \mathrm{ml})$. After 1 and 3 months of Se supplementation to HD patients, plasma element concentration increased significantly as compared with the initial value, to $102.4 \pm 28.8$ and $132 \pm 47.5$ $\mathrm{ng} / \mathrm{ml}$, respectively $(P<0.0001)$. In HD placebo group the Se concentration did not change (Fig. 1). Plasma

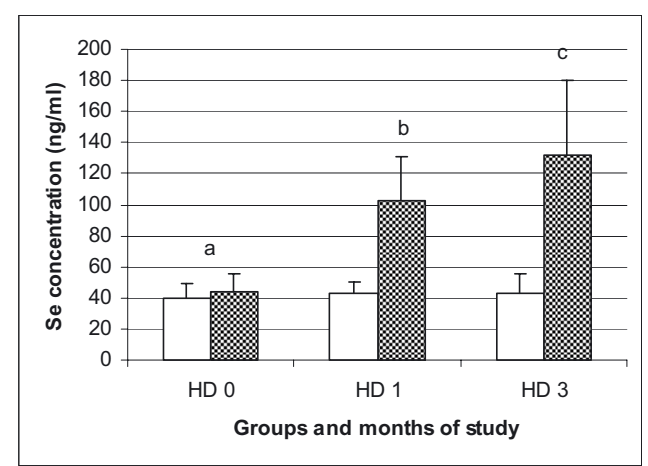

Figure 1. Plasma selenium concentration in healthy subjects and in CKD patients on HD supplemented with selenium and placebo.

CKD patients on hemodialysis at the beginning of the study (HD 0) and after 1 and 3 months (HD 1 and HD 3 , respectively) of Se or placebo supplementation. HD patients: white columns $=$ placebo, filled columns $=+$ Se. Statistics: a, $P<0.0001$ vs controls; $b, P<0.0001$ vs placebo group and initial values (HD 0), and $c, P<0.01$ vs HD 1. 


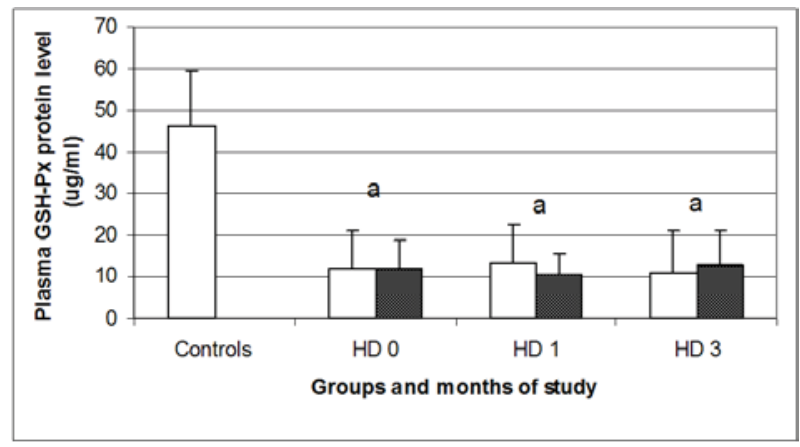

Figure 2. Plasma GSH-Px protein level in healthy subjects and in CKD patients on HD supplemented with selenium and placebo.

CKD patients on hemodialysis at the beginning of the study (HD 0 ) and after 1 and 3 months (HD 1 and HD 3 , respectively) of Se or placebo supplementation. HD patients: white columns $=$ placebo, filled columns $=+$ Se. Statistics: a, $P<0.0001$ vs controls.

GSH-Px protein level in both HD groups at the beginning of the study was $11.4 \pm 6.7 \mu \mathrm{g} / \mathrm{ml}$ and was 4.2 times lower as compared with healthy controls $(48.4 \pm 12.3 \mu \mathrm{g} / \mathrm{ml}$; Fig. 2$)(P<0.0001)$. During the 3 month period of the study, in both groups of HD patients (supplemented with Se and administered with placebo), the plasma GSH-Px protein level did not change significantly. Creatinine concentration in HD patients at the beginning of the study was $9.93 \pm 2.91 \mathrm{mg} / \mathrm{dL}$ and during the 3-month period of the study it did not change significantly in the Se supplemented group, or in the placebo group.

The correlations between some parameters of dialyzed patients at the beginning of the study (HD 0 ; both groups taken together) were as follows: Se concentration: GSH-Px protein level, $r=0.052$; creatinine concentration: GSH-Px protein level, $\mathrm{r}=-0.110$.

In CKD patients, plasma GSH-Px, an enzyme that is predominantly synthesized in the kidney (Chu et al., 1992; Avissar et al., 1994) plays an extremely important role. Some researchers (Ceballos-Picot et al., 1996; Yoshimura et al., 1996; Zachara et al., 2006) have shown that plasma GSH-Px activity in CKD patients decreases along with the progression of the disease. We obtained similar results in our previous studies (Zachara et al., 2000; 2004a; 2004b). So far only a few papers have been published on plasma GSH-Px protein level in CKD patients (Yamamoto et al., 1995; Yoshimura et al., 1996; Roxborough et al., 1999; Donica, 2001; Nishioka et al., 2001) and their results are inconsistent. Although Roxborough and coworkers (1999) found that plasma GSH-Px activity in HD patients was lower by $40 \%$ as compared with healthy people $(P<0.001)$, they did not observe any difference in plasma GSH-Px protein levels in those patients. The authors have shown that plasma GSH-Px protein level is the same in HD patients as in controls and remains unaltered during HD session. On the other hand, Nishioka et al. (2001) have shown that plasma GSH-Px protein level in hemodialyzed patients is $18.7 \%$ of that found in healthy volunteers (5.4 vs $28.8 \mu \mathrm{g} / \mathrm{ml}$ ) while Yamamoto and coworkers (1995) found 32\% of that obtained in controls (5.7 vs $17.8 \mu \mathrm{g} / \mathrm{ml})$. The results of our study, in percentage terms, are similar to the data published by Yamamoto and coworkers (1995). The authors believe that a lower level of plasma GSH-Px protein may reflect its decreased synthesis in the damaged kidney tissue. Quite different are the results presented by Yoshimura and coworkers (1996), who showed that in nondialyzed CKD patients with low plasma GSH-Px activity, plasma GSH-Px protein level was strongly reduced or even undetectable. These authors assumed that the reduced plasma GSH-Px protein level was due to an impaired synthesis of the enzyme in the kidney or its enhanced catabolism. Since in their patients plasma Se concentration was within the normal range, they proposed that the low plasma GSH-Px activity was not due to low Se concentration, as some authors think (Richard et al., 1993), but to the decreased concentration of GSH-Px protein in the plasma.

Our data seem to support the conjecture of Yoshimura and coworkers (1996). We believe this may be the case owing to the fact that in our patients, after 3 months of Se supplementation, the element concentration in plasma was 3 times higher than at the beginning of the study, but GSH-Px protein level, which was extremely low at the start of the study, did not undergo any change. This may indicate that in the end-stage of CKD, the damaged renal tubules are unable to synthesize this enzyme, even after supplementation with Se.

The novelty of our study is the lack of effect of Se supplementation on the GSH-Px protein level in plasma of CKD patients on HD. In healthy subjects with low blood Se concentration Se supplementation increases the activity of plasma GSH-Px (Xia et al., 1992). The activity kept increasing in direct proportion to the amount of Se supplied until it reached its optimal value (Saint-Georges et al., 1989).

The estimates of the level of GSH-Px protein in plasma of healthy persons determined with the enzyme-linked immunosorbent assay (ELISA) reported by different authors are highly divergent. Roxborough and coworkers (1999), Yamamoto and coworkers (1995) and quite recently Jacobson and coworkers (2006) obtained almost identical results (15.2, 17.8 and $18.5 \mu \mathrm{g} / \mathrm{ml}$, respectively), but their values were 2.5 to 3 times lower than ours $(48.4 \mu \mathrm{g} /$ $\mathrm{ml}$ ). Nishioka and coworkers (2001) found $28.8 \mu \mathrm{g} /$ ml, while McGill and coworkers (2003) obtained 63 $\mu \mathrm{g} / \mathrm{ml}$ in healthy subjects. Surprisingly, a very high level of plasma GSH-Px protein $(6.04 \mathrm{mg} / \mathrm{ml})$ was re- 
ported in Poland by Donica (2001). Despite the very high value of this enzyme, this author, similarly as Roxborough et al. (1999), reported that the level of GSH-Px protein in patients on HD $(5.97 \mathrm{mg} / \mathrm{ml})$ did not differ from that found in healthy persons.

Our results on the effect of Se supplementation to HD patients on GSH-Px protein level are the first ones published to date. Along with the kidney, GSH-Px 3 is also synthesized, in small amounts, in the liver, lung, heart, breast, intestine, brain, skeletal muscle and placenta, from which it is secreted into the extracellular fluid (Chu et al., 1992; Avissar et al., 1994). Nevertheless, the plasma GSH-Px level largely depends on renal function (Nishioka et al., 2001). Consequently it comes as no surprise that the protein level of this enzyme is low in CKD patients, and that this becomes increasingly pronounced with the progress of the disease, reaching a maximum in the end-stage of the disease. Our patients showed high creatinine concentrations ranging from 5.4 and $16.6 \mathrm{mg} / \mathrm{dL}$, yet there was no significant relationship between creatinine level and GSH-Px protein level. Nor did we observe any relationship between Se concentration and GSH-Px protein level.

As was mentioned above, Se supplementation in healthy subjects induces GSH-Px synthesis in the tissues. With that in mind we set out to determine the effect of Se supplementation on GSHPx 3 protein in patients with CKD on HD. A lack of stimulation of GSH-Px 3 synthesis in the kidneys after Se supplementation does not mean that other glutathione peroxidases are not synthesized in other tissues. Se supplementation may thus have a beneficial effect on the body's antioxidative defense system by inducing GSH-Px synthesis in other tissues. Indeed, some authors (Nishioka et al., 2001) suggest that CKD patients should be given selenium already in the early stages of the disease.

In summary, our data show that Se supplementation to CKD patients on HD has no effect on the level of plasma GSH-Px protein.

\section{Acknowledgements}

This study was financially supported by the State Committee for Scientific Research (KBN, Warszawa, Poland) (Grant No. 2 P05D 097 27). B.A.Z. expresses his gratitude to the Foundation for Polish Science (FNP, "Nestor") for providing an individual grant. Part of the results were presented at a meeting of the International Society for Trace Element Research in Humans, Crete, Greece, October 21-26, 2007.

Thanks are due to Mr. Sven Moesgaard, Pharma Nord, Denmark, for supplying us with seleniumrich-yeast and placebo used in this study.

\section{REFERENCES}

Avissar N, Ornt DB, Yagil Y, Horovitz S, Watkins RH, Kerl EA, Takahashi K, Palmer IS, Cohen HJ (1994) Human kidney proximal tubules are the main source of plasma glutathione peroxidase. Am J Physiol (Cell Physiol) 266: C367-C375.

Brigelius-Flohe R (2006) Glutathione peroxidases and redox-regulated transcription factors. Biol Chem 387: 1329-1335.

Ceballos-Picot I, Witko-Sarsat V, Merad-Boudia M, Nguyen AT, Thevenin M, Jaudon MC, Zingraff J, Jungers P, Descamps-Latscha B (1996) Glutathione antioxidant system as a marker of oxidative stress in chronic renal failure. Free Rad Biol Med 21: 845-853.

Chu FF, Esworthy S, Doroshow JH, Doan K, Liu XF (1992) Expression of plasma glutathione peroxidase in human liver in addition to kidney, heart, lung, and breast in humans and rodents. Blood 79: 3233-3238.

Donica H (2001) Evaluation of lipid peroxidation products vs. proinflammatory cytokines in hemodialyzed patients. Renal Failure 23: 231-238.

Jacobson GA, Narkowicz C, Tong YC, Peterson GM (2006) Plasma glutathione peroxidase by ELISA and relationship to selenium level. Clin Chim Acta 369: 100-103.

Kyriakopoulos A, Behne D (2002) Selenium-containing proteins in mammalian and other forms of life. Rev Physiol Biochem Pharmacol 145: 1-46.

McGill CR, Green NR, Meadows MC, Gropper SS (2003) Beta-caroten supplementation decreases leukocyte superoxide dismutase activity and serum glutathione peroxidase concentration in humans. J Nutr Biochem 14: 656-662.

Morrison DF (1990) Multivariate Statistical Methods (Polish edn). PWN, Warsaw.

Neve J, Chamart S, Molle L (1987) Optimization of direct procedure for the determination of selenium in plasma and erythrocytes using Zeeman effect atomic absorption spectroscopy. In Trace Elements Analytical Chemistry in Medicine and Biology, Bratter P, Schramel P, eds, 4: pp 349-358. Walter de Gruyter, Berlin.

Nishioka H, Kanauchi M, Dohi K (2001) The role of extracellular glutathione peroxidase in diabetic nephropathy. Nephron 87: 196-197.

Papp LV, Lu J, Holmgren A, Khanna KK (2007) From selenium to selenoproteins: Synthesis, identity, and their role in human health. Antioxid Redox Signal 9: 775-806.

Richard MJ, Duclos V, Foret M, Arnaud J, Coudray C, Fusselier M, Favier A (1993) Reversal of selenium and zinc deficiencies in chronic hemodialysis patients by intravenous sodium selenate and zinc gluconate supplementation. Time-course of glutathione peroxidase repletion and lipid peroxidation decrease. Biol Trace Elem Res 39: 149-159.

Rico MG, Puchades MJ, Ramon RG, Saez G, Tormos MC, Miguel A (2006) Effect of hemodialysis on oxidative stress in patients with chronic renal failure. Nefrologia 26: $218-225$.

Roxborough HE, Mercer C, McMaster D, Young IS (1999) Plasma glutathione peroxidase activity is reduced in haemodialysis patients. Nephron 81: 278-283.

Saint-Georges MD, Bonnefont DJ, Bourely BA, Jaudon MC, Cereze P, Chaumeil P, Gard C, D’Auzac CL (1989) Correction of selenium deficiency in hemodialyzed patients. Kidney Int (Suppl) 27: S274-S277.

Xia Y, Hill KE, Byrne DW, Xu J, Burk RF (2005) Effectiveness of selenium supplementation in a low-selenium area of China. Am J Clin Nutr 81: 829-834. 
Xia Y, Zhao X, Zhu L, Whanger PD (1992) Metabolism of selenate and selenomethionine by a selenium-deficient population of men in China. J Nutr Biochem 3: 202-210.

Yamamoto Y, Takekoshi Y, Itami N (1995) Enzyme-linked immunosorbent assay for extracellular glutathione peroxidase in serum of normal individuals and in patients with renal failure on hemodialysis. Clin Chim Acta 236: 93-99.

Yoshimura S, Suemizu H, Nomoto Y, Sakai H, Katsuoka Y, Kawamura N, Moriuchi T (1996) Plasma glutathione peroxidase deficiency caused by renal dysfunction. $\mathrm{Ne}$ phron 73: 207-211.

Zachara BA, Adamowicz A, Trafikowska U, Pilecki A, Manitius J (2000) Decreased plasma glutathione peroxidase activity in uremic patients. Nephron 84: 278-279.

Zachara BA, Gromadzińska J, Wąsowicz W, Zbróg Z (2006) Red blood cell and plasma glutathione peroxi- dase activities and selenium concentration in patients with chronic kidney disease: A review. Acta Biochim Polon 53: 663-677.

Zachara BA, Koterska D, Manitius J, Sadowski L, Dziedziczko A, Salak A, Wasowicz W (2004a) Selenium supplementation on plasma glutathione peroxidase activity in patients with end-stage chronic renal failure. Biol Trace Elem Res 97: 15-30.

Zachara BA, Salak A, Koterska D, Manitius J, Wasowicz W (2004b) Selenium and glutathione peroxidases in blood of patients with different stages of chronic renal failure. J Trace Elem Med Biol 17: 291-299.

Zima T, Mestek O, Nemecek K, Bartova V, Fialova J, Tesar $\mathrm{V}$, Suchanek M (1998) Trace elements in hemodialysis and continuous ambulatory peritoneal dialysis patients. Blood Purif 16: 253-260. 